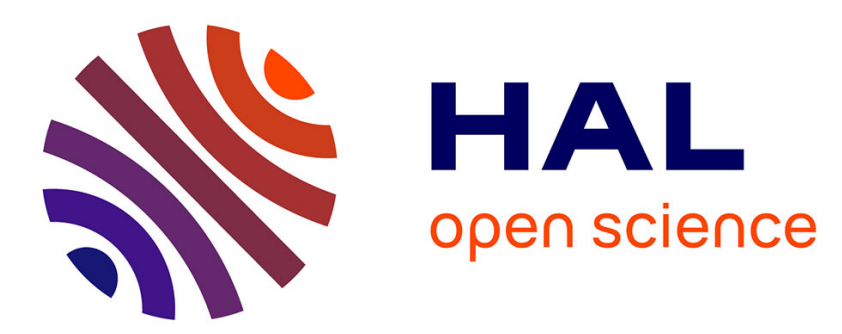

\title{
Thermoporosimetry: a powerful tool to study the cross-linking in gels networks
}

\author{
Jean-Marie Nedelec, Jean-Pierre E. Grolier, Mohamed Baba
}

\section{To cite this version:}

Jean-Marie Nedelec, Jean-Pierre E. Grolier, Mohamed Baba. Thermoporosimetry: a powerful tool to study the cross-linking in gels networks. Journal of Sol-Gel Science and Technology, 2006, 40, pp.191-200. 10.1007/s10971-006-9115-y . hal-00154680

\section{HAL Id: hal-00154680 \\ https://hal.science/hal-00154680}

Submitted on 14 Jun 2007

HAL is a multi-disciplinary open access archive for the deposit and dissemination of scientific research documents, whether they are published or not. The documents may come from teaching and research institutions in France or abroad, or from public or private research centers.
L'archive ouverte pluridisciplinaire HAL, est destinée au dépôt et à la diffusion de documents scientifiques de niveau recherche, publiés ou non, émanant des établissements d'enseignement et de recherche français ou étrangers, des laboratoires publics ou privés. 


\section{Submitted to the 2005 Workshop Special Issue}

\section{Thermoporosimetry: a powerful tool to study the cross-linking in gels networks}

Jean-Marie Nedelec ${ }^{1 *}$, Jean-Pierre E. Grolier ${ }^{2}$ and Mohamed Baba ${ }^{3}$

${ }^{1}$ Laboratoire des Matériaux Inorganiques, UMR CNRS 6002

${ }^{2}$ Laboratoire de Thermodynamique des Solutions et des Polymères, UMR CNRS 6004

${ }^{3}$ Laboratoire de Photochimie Moléculaire et Macromoléculaire, UMR CNRS 6505

TransChiMiC

Ecole Nationale Supérieure de Chimie de Clermont Ferrand \& Université Blaise Pascal, 24 Avenue des landais 63177 Aubière Cedex FRANCE.

\footnotetext{
* Corresponding author :

E-mail j-marie.nedelec@univ-bpclermont.fr

Phone $0033(0) 473407105$

Fax $0033(0) 473407108$
} 


\begin{abstract}
In this paper, alternative techniques for the measurement of porosity based upon GibbsThomson equation are reviewed and discussed. The paper focuses on thermoporosimetry trying to demonstrate that it is a valuable tool relevant to sol-gel science. A detailed calibration procedure using sol-gel derived silica gels is presented for acetone. It is then shown that it is possible to predict the behaviour of confined liquids related to a given chemical family. Finally two selected examples illustrate the great potential of this technique for the study of gels networks and cross-linking. Perspectives concerning the study of organic-inorganic hybrids materials are finally given.
\end{abstract}

Keywords: thermoporosimetry, confinement, mesoporous, gels, cross linking, nanostructured materials, soft matter, organic-inorganic hybrid materials 


\section{Introduction}

Porous materials are solids made up of interconnected networks of pores delimited by solid walls. These materials are omnipresent in nature and find various industrial applications. Numerous biological processes also involve such porous materials making them the object of abundant studies. The characterization of porosity is therefore a crucial issue.

Numerous techniques have consequently been developed to characterize the texture of porous solids. Among them, gas sorption and mercury intrusion porosimetry are probably the most popular. Alternative techniques relying on the Gibbs-Thomson equation [1,2] have also been proposed. This equation quantifies the observed experimental shift of the melting point of a liquid confined in pores and can be written:

$$
\Delta T=T_{p}-T_{0}=\frac{2 \sigma_{s L} \cos \theta T_{0}}{\Delta H_{m} \rho_{s} R_{p}} \approx \frac{k}{R_{p}} \quad(\text { Equation 1) }
$$

where $T_{p}$ is the melting temperature of a liquid confined in a pore of radius $R_{p}, T_{0}$ is the normal melting temperature of the liquid, $\sigma_{\mathrm{SL}}$ is the surface energy of the solid/liquid interface, $\theta$ the contact angle, $\Delta \mathrm{H}_{\mathrm{m}}$ is the melting enthalphy and $\rho_{\mathrm{S}}$ the density of the solid.

According to this equation, the shift of the transition temperature of a confined liquid $\Delta \mathrm{T}$ is inversely proportional to the radius of the pore in which it is confined. In fact it is well known that not all the solvent takes part in the transition and that a significant part of it remains adsorbed on the surface of the pore. The state of this adsorbed layer has been discussed extensively in the case of water. Consequently, the radius measured by application of the Gibbs-Thomson equation should be written $\mathrm{R}=\mathrm{R}_{\mathrm{p}} \mathrm{t}$ where $\mathrm{t}$ is the thickness of the adsorbed layer leading to a reformulation [3] of Equation 1 as

$$
R_{p}=\frac{k}{\Delta T}+t \quad(\text { Equation } 2)
$$

In principle, it is then possible to determine the pore size of a given material by measuring $\Delta \mathrm{T}$. In 1955 Kuhn et al. [4] proposed to use Differential Scanning Calorimetry to measure $\Delta \mathrm{T}$ 
and invented the so called thermoporometry technique (or thermoporosimetry as will be used in the following). This technique has been further described by Fagerlund [5] and popularized and developed by Brun [6]. In 1969, Derouane et al. [7] published the first measurement of liquid water content by NMR in a partially frozen sample. In 1993, Strange et al. [8] proposed to measure $\Delta \mathrm{T}$ by NMR technique giving birth to NMR Cryoporometry. The two techniques despite their historical and confusing different names are indeed very similar from a theoretical point of view. If the measurement of $\Delta \mathrm{T}$ is direct in the case of $\mathrm{DSC}$, the situation is quite different for NMR cryoporometry. The basis of the later is the measurement of the fractions of frozen and unfrozen liquids as a function of temperature. In such an experiment, the porous sample is cooled down enough to freeze all the liquid inside the pores. The sample is then slowly heated up and the NMR signal of the mobile protons from the solvent is recorded. The intensity of this signal obviously increases as the fraction of liquid solvent increases during the heating process. When all the confined solvent is melted the signal becomes constant before increasing again when the temperature reaches the normal melting temperature of the excess solvent. Knowledge of $\mathrm{k}$ in Equation 2 is mandatory, but once determined, the curve obtained from NMR cryoporometry can be transformed into the pore size distribution. In this sense, thermoporosimetry and NMR cryporometry are secondary methods since they require preliminary determination of the evolution of $\Delta \mathrm{T}$ as a function of $\mathrm{R}_{\mathrm{p}}$ for a given solvent.

Thermoporosimetry is obviously much simpler to perform when compared to NMR cryoporometry. The cost of the equipment is also much lower. Nevertheless, NMR cryoporometry continues to develop under the efforts of some groups $[9,10]$. The use of ${ }^{129} \mathrm{Xe}$ NMR of xenon dissolved in confined organic solvents [11] seems to be particularly promising and offers new possibilities. One of the main advantages of NMR cryoporometry that makes it unique, is the possibility to combine the NMR experiment with standard NMR imaging 
techniques $[12,13,14]$. This offers the possibility to get spatial resolution in all three dimensions on a macroscopic scale $(100 \mu \mathrm{m}-10 \mathrm{~mm})$. Up to now, and to the best of our knowledge, this is the only technique able to give spatially resolved pore size distributions. This is of considerable interest in fields such as geology, biology, and materials science. It has been shown [15] that the correlation between gas sorption, thermoporosimetry and NMR cryporometry is good making the later two interesting alternatives for measuring pore size distribution. At this point, it must be noticed that application of Gibbs-Thomson equation to measure PSD is limited to pore radius higher than $1 \mathrm{~nm}$ (the limit depends strongly on the nature of the solvent).

The aim of this paper is to report recent developments of thermoporosimetry that make it, in our opinion, a technique deserving much attention. In particular, we will show how thermoporosimetry can give important information about the reticulation of gels networks. It will also be shown that for reasonably similar solvents, calibration procedures can be avoided making this technique even more attractive. Our calibration procedure using sol-gel derived mesoporous silica will be firstly exemplified with acetone. Two different examples concerning cross linked polyolefins and aged silicones will illustrate how thermoporosimetry can be used efficiently on gels networks. Perspectives will be given concerning hybrid organic-inorganic materials.

\section{Experimental section}

\subsection{Calibration Porous Materials}

Nanoporous monolithic silica gels $(2.5 \mathrm{~mm} \times 5.6 \mathrm{~mm}$ diameter cylinders $)$ were prepared by the acid catalysed hydrolysis and condensation of a silicon alkoxide, following procedures reviewed elsewhere [16]. Careful control of the aging time performed at $900^{\circ} \mathrm{C}$ allowed the production of samples with controlled textural properties. In this study four samples (1-4) 
with different textural properties (Specific Surface Area (SSA), total pore volume $\left(\mathrm{V}_{\mathrm{p}}\right)$ and pore size distribution (PSD)) were used. The textural characteristics of the samples were determined by $\mathrm{N}_{2}$ sorption.

\subsection{Gas sorption measurements}

Textural data of the silica gels were determined on a Quantachrome Autosorb 1 apparatus. The instrument permits a volumetric determination of the isotherms by a discontinuous static method at $77.4 \mathrm{~K}$. The adsorptive gas was nitrogen with a purity of $99.999 \%$. The cross sectional area of the adsorbate was taken to be $0.162 \mathrm{~nm}^{2}$ for SSA calculations purposes [17]. Prior to $\mathrm{N}_{2}$ sorption, all samples were degassed at $100^{\circ} \mathrm{C}$ for $12 \mathrm{~h}$ under reduced pressure. The masses of the degassed samples were used in order to estimate the SSA. The BET [18] SSA was determined by taking at least 4 points in the $0.05<\mathrm{P} / \mathrm{P}_{0}<0.3$ relative pressure range. The pore volume was obtained from the amount of nitrogen adsorbed on the samples up to a partial pressure taken in the range $0.994<\mathrm{P} / \mathrm{P}_{0}<0.999$. Pore size distributions were calculated from the desorption isotherm by the $\mathrm{BJH}$ method [19]. The mean pore radius $\mathrm{R}_{\mathrm{av}}$ was calculated according to

$$
R_{a v}=\frac{2 V_{p}}{S_{B E T}} \quad \text { (Equation 3) }
$$

corresponding to a cylindrical shape for the pores.

Textural data for the different samples are displayed in Table 1. In this table, the modal pore diameter $\mathrm{R}_{\mathrm{p}}$ is also shown and this value was used for the DSC calibration. This value fairly matches the $R_{a v}$ derived from $S_{B E T}$ measurement with cylindrical shape assumption thus confirming the validity of the hypothesis on the pore shape. 


\subsection{DSC measurements}

A Mettler-Toledo DSC30 instrument calibrated (both for temperature and enthalpy) with metallic standards ( $\mathrm{In}, \mathrm{Pb}, \mathrm{Zn}$ ) and with n-heptane was used to record the thermal curves. It was equipped with a Nitrogen liquid set allowing a scanning range of temperature between 170 and $600{ }^{\circ} \mathrm{C}$. About 10 or $20 \mathrm{mg}$ of the studied material were introduced into a DSC pan to undergo an appropriate temperature program. As recommended by Brun [6] and recalled recently by Landry [20] and as performed in our previous work, the measurement is performed following the following thermal cycle. The sample is first cooled down at a temperature low enough to freeze all liquid (free and confined) and then heated up slowly at a temperature just below the equilibrium melting point until only the confined solvent is melt. Doing this, the unconfined solvent remains under solid state and acts as seeds to the crystallisation of the confined liquid following further cooling. To allow the system to be in an equilibrium state, a slow freezing rate is required, a rate of $-0.7^{\circ} \mathrm{C} / \mathrm{min}$ was chosen. Other slower cooling rates have been tested not showing any significant discrepancy.

\section{Results and discussion}

\subsection{Calibration and Pore Size Distribution (PSD) measurement}

The whole DSC curve is indeed representative of the pore size distribution of a given sample.

From Equation 2 or its empirical corresponding relationship and the DSC thermogram, pore size distributions (PSD) can be derived as follows:

$$
\frac{d\left(V_{p}\right)}{d\left(R_{p}\right)}=\frac{d Q(T)}{d t} \frac{d t}{d(\Delta T)} \frac{d(\Delta T)}{d\left(R_{p}\right)} \frac{1}{W_{a}(T)} \quad \text { (Equation 4) }
$$

where $V_{p}\left(\mathrm{~cm}^{3} \cdot \mathrm{g}^{-1}\right)$ is the pore volume, $d Q(T) / d t\left(\mathrm{~W} \cdot \mathrm{g}^{-1}\right)$ is the heat flow per gram of the dry porous sample given by the ordinate of DSC thermogram, $d t / d(\Delta T)\left(\mathrm{s} \cdot \mathrm{K}^{-1}\right)$ is the reverse of the 
cooling rate, $d(\Delta T) / d\left(R_{p}\right)\left(\mathrm{K}_{\mathrm{nm}} \mathrm{nm}^{-1}\right)$ is derived from the empiric relationship corresponding to Equation 1 and $W_{a}(T)\left(\mathrm{J} . \mathrm{cm}^{-3}\right)$ is the apparent energy as defined by Brun. Equation 4 is similar to that proposed by Landry [20]. However, the specific energy of crystallization is temperature dependent and, in addition, all the solvent does not take part in the thermal transition since, as stated before, a layer of the solvent remains adsorbed on the internal wall of the pores. Only an apparent energy $\left(\mathrm{W}_{\mathrm{a}}\right)$ can be calculated, dividing the total heat, released by the thermal transition, by the total volume or mass of the confined solvent.

In order to reach the PSD calculation, it is necessary to establish the temperature dependence of both $R_{p}$ and $W_{a}$. In the following original results concerning acetone will be given. In the last three years, numerous solvents have been calibrated for thermoporosimetry including acetonitrile [21], $\mathrm{CCl}_{4}$ [22,23], xylenes, substituted benzenes [24], linear alkanes [25], cyclohexane [26], dioxane [27], completing initial data published for water and benzene.

Using the silica gels described in section 2, it has been possible to derive the $R_{p}=f(\Delta T)$ and $\mathrm{W}_{\mathrm{a}}=\mathrm{f}(\Delta \mathrm{T})$ laws. DSC thermograms recorded for acetone confined in the various silica gels samples are shown in Figure 1. The experimental $\Delta \mathrm{T}$ values are given in Table 1 for the different silica samples.

[Figure 1 around here]

Resulting calibration curves are displayed in Figure $2 a$ and $2 b$ for $R_{p}$ and $W_{a}$ respectively. Experimental data have been fitted with following laws:

$$
\begin{array}{ll}
R_{p}=t \cdot \exp ^{\left(\frac{c}{\Delta T}\right)} & (\text { Equation 5) } \\
W_{a}=W_{0} \cdot \exp ^{\left(\frac{\Delta T}{f}\right)} & (\text { Equation 6) }
\end{array}
$$


$c$ and $f$ are constants depending on the solvent. $W_{0}$ is the energy of crystallization of the bulk solvent at its normal solidification temperature and $t$ is the thickness of the layer of adsorbed solvent. Orthogonal Distance Regression (ODR) minimizing for each point the distance between the fitting curve and the experimental points has been performed on the data. The corresponding curve is plotted in Figure 2 together with the corresponding Kelvin equation fit. ODR of the experimental data gives, $\mathrm{c}=-23.9 \mathrm{~K} \mathrm{t}=16.3 \AA$ and $\mathrm{f}=20.696 \mathrm{~K} . \mathrm{W}_{0}$ was taken and fixed from the value measured for the free acetone $\mathrm{W}_{0}=80.54 \mathrm{~J} . \mathrm{cm}^{-3}$.

It is indeed striking to note that in the case of Kelvin equation, the fit gives a meaningless negative $t$ value. Our experimental model, even if it differs from the Kelvin equation, in particular for the high value of $\mathrm{R}_{\mathrm{p}}$, appears to be a better extrapolation of experimental data. Furthermore, it is worthy to note that this equation is very consistent with limits behaviors. In effect, when $\Delta \mathrm{T}$ tends towards $+\infty, \mathrm{R}_{\mathrm{p}}$ tends towards $\mathrm{t}$ the value of the adsorbed layer and when $\Delta \mathrm{T}$ is zero $\mathrm{R}_{\mathrm{p}}$ tends towards $+\infty$ (the solvent is no longer confined the pore is infinite). This model has proven to be the most suitable for other solvents like substituted benzenes or alkanes [24,25]. Obviously, the choice of the model has little influence for small pores but becomes critical for extrapolation towards higher values.

[Figure 2 around here]

These calibration curves have been validated on a porous alumina sample. The PSD measured by nitrogen gas sorption and by thermoporosimetry with acetone are shown in Figure 3 showing good agreement and thus validating the approach.

[Figure 3 around here] 
Using similar procedures, various other solvents and in particular aromatic solvents have been calibrated [24].

\subsection{Calibration less use of thermoporosimetry}

A strong drawback of thermoporosimetry (and of NMR cryoporometry consequently) is the required calibration procedure for a given solvent. We have shown in recent work that for solvents belonging to a specific chemical family, it is possible to extrapolate the temperature of crystallization of the solvent confined in a given pore with the simple knowledge of its normal transition temperature $\mathrm{T}_{0}$. Law of the type :

$$
T_{p}=A \cdot T_{0}+\frac{B}{R_{p}} \quad \text { (Equation 7) }
$$

has been derived for both substituted benzenes [24] and for linear alkanes [25]. In this equation $T_{p}$ is the crystallization temperature of the solvent confined in a pore of radius $R_{p}$ and $\mathrm{T}_{0}$ is the crystallization temperature of the free solvent. A and B are two constants which depend only on the type of solvent. Calibration over a wide range of solvents gives $A=1.02$ and $B=-1924.1 \mathrm{~K} . \AA^{-1}$ for substituted benzenes and $A=1.04$ and $B=-1251.2 \mathrm{~K} . \AA^{-1}$ for linear alkanes. Deviation from the $\Delta \mathrm{T}=\mathrm{k} / \mathrm{R}_{\mathrm{p}}$ Gibbs-Thomson equation coming from the deviation of A from the unit, reflects the existence of the adsorbed layer on the surface of the pores which does not takes part in the transition. Giving a unique equation for all solvents belonging to a given family implies the assumption that the thickness $t$ of this layer does not significantly vary from one solvent to another. For substituted benzenes and linear alkanes, this assumption is justified if one considers the $t$ values obtained from the calibration curves and given in Table 2.

The physical meaning of B is also interesting if one considers Equation 1. Our experimental results seem to indicate that the ratio $\sigma_{\mathrm{SL}} \cdot \operatorname{Cos} \theta \cdot \mathrm{T}_{0} / \Delta \mathrm{H}_{\mathrm{m}} \cdot \rho_{\mathrm{S}}$ is constant for all solvents 
belonging to the same family. Indeed all terms in this ratio are known to vary with temperature and with the solvent but it seems that all evolutions compensate each other for solvents that are closely related from a chemical point of view.

From the derived expression (Equation 7), it is possible to predict $T_{p}$ for a solvent belonging to the same family knowing $\mathrm{T}_{0}$. A comparison of the values of $\Delta \mathrm{T}=\mathrm{T}_{\mathrm{p}}-\mathrm{T}_{0}$ predicted by our model and measured experimentally is performed in Figure 4 for various substituted benzenes.

The correlation is very good attesting the validity of the model. It is also worthy to note that on this curve, the toluene has not been calibrated and consequently not been taken into account to obtain the $\mathrm{T}_{\mathrm{p}}=1.02 \mathrm{~T}_{0}-1924.1 / \mathrm{R}_{\mathrm{p}}$ law attesting the predictive value of the model.

[Figure 4 around here]

Of course the validity of this empirical model is limited to the pore size range used for its determination. Clearly this model is not valid for extrapolation towards high $\mathrm{R}_{\mathrm{p}}$ values where the sign of $\Delta \mathrm{T}$ changes according to Equation

The possibility to extrapolate $T_{p}$ for various solvents is very attractive and could allow in particular using thermoporosimetry using solvents previously un-calibrated.

\subsection{Application of thermoporosimetry to organic gels networks}

When a polymer is put into one of its good solvents, the latter tends to disperse the macromolecular chains. The ability of the solvent to disperse the molecular chains is related to the degree of repulsion that polymeric segments can develop between each others. The Flory-Huggins parameter $\chi$ allows quantification of this repulsion: the smaller the $\chi$, the better the solvent. 
Upon cross linking, the dispersion of polymeric chains is hindered. Covalent bridges, established between the macromolecules, have a certain elasticity giving them the possibility to be spread out or contracted following the solicitation. Between the natural tendency of the solvent to disperse the polymeric chains and the elastic response of the covalent cross links, an equilibrium state is found, characterized by a degree of swelling. A polymeric gel is then formed, constituted by a three-dimensional network whose Mesh Size Distribution (MSD) characterizes the cross linking level. For a given polymer, with a given cross liking level, the larger the mesh sizes, the better the solvent. The swelling ability of a given polymeric gel is closely related to its cross linking level. The knowledge of the cross linking level of a given polymer is fundamental since macroscopic properties such as the mechanical ones depend strongly on the cross linking level. Upon aging, the cross linking in polymers evolves considerably thus affecting its properties. It is therefore crucial to measure this cross linking level in order to predict the effect of aging on the behavior of polymers. Classically, the polymer aging is followed by spectrophotometric methods (mainly Fourier Transform Infra Red spectroscopy) which detect and quantify the oxidation products such as ketones, peroxides and other oxygenated structures. Nevertheless, apparition of these products is always initiated by the production of a radical, which can yield, either oxygenated structures or cross linking bond by recombination. The carbon-carbon bonds, which are the main cross linking source, are difficult to detect by spectrophotometry. Conventional methods such as swelling give only a mean characteristic values like the molecular weight between knots (Mc).

We have been recently using thermoporosimetry as a tool to study the cross linking in gels networks $[28,29]$ as proposed for the first time by Kuhn [4].

The application of thermoporosimetry to swollen gels is based on the formal analogy assumed between the notion of the pore in the rigid material and the concept of mesh in the polymeric 
network. The organic swollen network exerts a confinement action on the swelling solvent very similar to that exerted by any porous medium exhibiting an interconnected porosity. Using thermoporosimetry it is therefore possible to measure the MSD of a given gel network in a particular swelling state.

Scherer and co-workers $[30,31]$ reported that a shrinkage can occur when the swelling liquid crystallizes in particular for soft networks. Depending on the bulk modulus of the material $\mathrm{K}_{0}$ and on the mesh radius $\mathrm{R}$, the error might be very important (as high as ten times for soft materials and small radius). Anyway, even if the swollen gel experiences dimensional fluctuations because of the thermal transition of the liquid-probe, these variations must be small compared to the ones induced by swelling. Furthermore, mesh size associated with swollen polymeric networks is usually quite large, the error in this case is minimized. For the two considered polymers, the value of the bulk modulus $\mathrm{K}_{0}$ is not so low $\left(\mathrm{K}_{0}=140 \mathrm{MPa}\right.$ for polyethylene and $\mathrm{K}_{0}=53 \mathrm{MPa}$ for silicone). $\mathrm{K}_{0}$ value for medium density Polyethylene has been taken from the literature and for silicone it has been calculated from the Young modulus and Poisson's coefficient given by the polymer supplier. The same value has been taken for swollen and dry gel inducing some uncertainty but we do not have any experimental way for measuring the $\mathrm{K}_{0}$ value of the swollen polymer. In a similar way, the same value (the one of the starting material) has been used for the silicone sample showing different cross-linking levels, in this case, the error does not affect our conclusion since the modulus of the more reticulated sample must be higher than the one of the initial polymer thus leading to a smaller contraction of the network.

Combining high $\mathrm{K}_{0}$ and $\mathrm{R}$ values, the error is kept very low. It is completely negligible for polyethylene and will be calculated for the silicone sample. Thermoporosimetry consequently remains an efficient and unique tool to compare the relative state of cross linking of different gels networks. The mesh sizes distributions calculated from the thermoporosimetry formalism 
reflect the actual state of the sample taking in account the eventual shrinkage and the swelling equilibrium.

We will illustrate the use of thermoporosimetry in polymer science in the two following examples.

\subsubsection{Cross linking of polyolefins}

Polyolefin samples have been cross linked at different levels and their MSD have been measured by thermoporosimetry with para-xylene. A commercial polymer based on a mixture of a polypropylene homopolymer and an ethylene-propylene copolymer has been cross linked in various conditions. The sample has been irradiated with high energy electrons $(2.2 \mathrm{MeV})$ with a Van de Graaff apparatus up to $1000 \mathrm{kGy}$. This sample has also been irradiated with $\gamma$ rays from ${ }^{60} \mathrm{Co}(1.17 \mathrm{MeV}$ and $1.33 \mathrm{MeV})$ with different doses. The samples have been swollen in para-xylene at $138{ }^{\circ} \mathrm{C}$ for one night. Table 3 gives the irradiation doses and the swelling ratios of the different samples. The swelling ratio $G$ is defined as the ratio between the volume of the swollen gel and the volume of the dry gel as measured by gravimetry after soaking the dry gel in para-xylene.

[Table 3 around here]

MSD have been measured for all samples with para-xylene. The maximum of the MSD $\mathrm{R}_{\text {Max }}$ is given for each sample in Table 3. Upon increasing irradiation dose, one can observe a decrease of $\mathrm{G}$ along with a decrease of $\mathrm{R}_{\text {Max }}$. These observations are in agreement with the subsequent cross linking increase upon irradiation. $\mathrm{G}$ and $\mathrm{R}_{\text {Max }}$ decrease correlatively. Indeed, a correlation between $\mathrm{R}_{\operatorname{Max}}{ }^{3}$ and $\mathrm{G}$ can be expected in a first approximation since the volume of the confined solvent (volume of the mesh) is supposed to be proportional to $\mathrm{R}_{\mathrm{Max}}{ }^{3}$ and so is 
G. This correlation is presented in Figure 5 showing the evolution of $\mathrm{R}_{\mathrm{Max}}{ }^{3}$ as a function of $\mathrm{G}$. The experimental data can be fitted with an exponential growth as drawn in Figure 5. From this curve it is possible to extrapolate the value of $R_{\mathrm{Max}}$ for $\mathrm{G}=1$, the value corresponding to a dry gel presenting the highest cross linking level. This value usually difficult to measure is found to be $R_{\text {Max }}=230 \AA$. The discrepancy between the observed correlation and the $R_{a v}{ }^{3} \propto G$ expected behavior can be compared to the behavior of aerogels as described in [30] where a direct proportionality between the radius $\mathrm{r}$ and the volume $\mathrm{V}$ is considered. The molecular motions involved in chain re-arrangement might be responsible for the observed behavior. Indeed, a linear fit of the $\mathrm{R}_{\max }=\mathrm{f}(\mathrm{G})$ curve is quite reasonable as shown in Figure 6 . The limitation of this fit comes from the negative value of $R$ given by the fit for $G=1$. The fit retained in Figure 5 is more consistent.

In any case, the correlation between $G$ and $R_{a v}$ is clear making $R_{a v}$ a valuable variable to discuss the evolution of a given network.

[Figure 5 around here]

[Figure 6 around here]

\subsubsection{Silicones}

A key issue in applied polymer science is the study and the prevision of polymer aging in their conditions of use (weathering, photo aging, electrical aging, thermo oxidation,...). The timescale of polymer aging is quite long. In order to study the effect of aging it is necessary to develop artificial accelerated aging procedures. The validity of such procedures is always questionable. 
In this study, a commercial silicone sample coming from an electrical device has been aged in working conditions for two years under a dry and hot climate in the desert. It has been manufactured by injection moulding at $170{ }^{\circ} \mathrm{C}$ for one minute. It is assumed that ageing of this material is accompanied by modification of the cross-linking level. To reproduce the cross-linking level of the naturally aged sample, a silicone rubber containing polydimethylsiloxane from Dow Corning was used. This sample was filled with $23 \% \mathrm{wt}$ silica and vulcanized with DCBP at $0.4 \%$ wt reproducing the reference sample composition. Vulcanization was performed at $170{ }^{\circ} \mathrm{C}$ for 1 and 12 minutes. The sample vulcanized for 1 minute is similar to the reference sample in its initial stage (before aging). The sample vulcanized for 12 minutes is expected to mimic the aged sample (same reticulation level) if our hypothesis is right. A $200 \mu \mathrm{m}$ thick slice of the three materials has been soaked in cyclohexane for two days. Cyclohexane has been calibrated for thermoporosimetry in our previous work [26] and the derived laws have been used in the present work with extrapolation towards higher radii when required. This solvent is particular since it presents a phase transition at low temperature in the solid state. This transition has been used instead of the liquid to solid transition because it is much more energetic. MSD of the three samples have been measured by thermoporosimetry and are presented in Figure 7.

[Figure 7 around here]

For a vulcanization time increasing from 1 to 12 minutes, the maximum of the MSD shifts from 310 to $140 \AA$ indicating clearly an increase of the cross linking level associated with a decrease of the mean mesh size. The MSD of the aged sample is quite similar to the one of the sample vulcanized for 12 minutes confirming our working hypothesis. For these samples, the contraction induced during freezing is very limited. Considering model of [30], the error is 
negligible for low reticulation level material and is about $10 \%$ (with an overestimated $\mathrm{K}_{0}$ value of $53 \mathrm{MPa})$ for the materials presenting the highest level of cross-linking $\left(\mathrm{K}_{0}>53 \mathrm{MPa}\right.$ and $\mathrm{R}=14 \mathrm{~nm}$ ). The error is quite low and in any case, the two samples showing the same distribution (MSD), even if an error exists on the value of the average mesh size $\mathrm{R}_{\mathrm{av}}$, this error is the same for both samples and does not modify our conclusions. From this study, it can be concluded that the ageing for this material is essentially due to an increase of the cross linking level. This conclusion is unusual for silicones which are believed to be very stable. In fact, thermoporosimetry appears to be most suitable for such measurement when compared to FTIR spectroscopy which is not directly sensitive to the evolution of cross linking.

\section{Conclusion and perspectives}

It has been shown that thermoporosimetry is an attractive technique for the study of confined liquids. We also demonstrated that it is possible, to some extent, to predict the behavior of confined liquids without having to perform a fastidious calibration. Thermoporosimetry also appear to be a very valuable technique for the study of gels networks. This point has been demonstrated on two selected examples concerning polyolefin and silicones presenting various degree of cross linking. Thermoporosimetry allows getting information on the organization of the network and on the mesh size distribution of the networks. By selecting solvents with different polarities, and thus different interactions with the gel, it is possible to get more information about the structure of the networks. In the case of organic-inorganic hybrids materials, the inorganic building block is usually well known from a structural point of view (titanium oxo-clusters for instance [32]) but the organization of the organic network is much more difficult to study. Thermoporosimetry could be a useful tool to perform such study. In the specific case of mesoporous hybrids materials, thermoporosimetry is expected to bring information both on the porosity and on the organic network in a single experiment. 
This aspect is under study in our group. The variety of now available solvents for thermoporosimetry should make this technique a very valuable tool to study self assembly processes, and hybrid materials formation on a mesoscopic scale.

\section{Acknowledgements}

The authors would like to thank one of the referees for his very useful and pertinent comments and thorough reading of our manuscript.

Financial support from the French ANR under project Nanothermomécanique (ACI Nanosciences $\mathrm{N}^{\circ} 108$ ) is gratefully acknowledged. 


\section{Tables and Figures captions}

Table 1: Textural data of the four nanoporous silica gels used for calibration.

Table 2: Thickness of the adsorbed layer $t$ for various solvents derived from calibration.

Table 3: Irradiation doses, swelling ratio $G$ and maximum of Mesh Size Distribution $\mathrm{R}_{\mathrm{Max}}$ for the polyolefin samples.

Figure 1: DSC curves recorded for free acetone and acetone confined in silica gels 1-4 and in porous alumina (dotted line).

Figure 2: Calibration curves of acetone using silica gels 1-4 for $\mathrm{R}_{\mathrm{p}}$ with Kelvin model (dotted line) and our model (continuous line) (Figure $2 \mathrm{a}$ ) and $\mathrm{W}_{\mathrm{a}}$ (Figure $2 \mathrm{~b}$ ).

Figure 3: Pore Size Distributions of reference porous alumina sample measured by nitrogen gas sorption (-o-) and by thermoporosimetry with acetone (-).

Figure 4: Correlation between experimental values of $\Delta \mathrm{T}$ measured with DSC $\left(\Delta \mathrm{T}_{\text {exp }}\right)$ and the $\Delta \mathrm{T}$ values predicted by our model $\left(\Delta \mathrm{T}_{\text {cal }}\right)$ for various aromatic solvents.

Figure 5: Correlation between $\mathrm{R}_{\operatorname{Max}}{ }^{3}$ and the swelling ratio $\mathrm{G}$ for the various polyolefin samples. The dotted line corresponds to the best exponential growth fit.

Figure 6: Correlation between $\mathrm{R}_{\mathrm{Max}}$ and the swelling ratio $\mathrm{G}$ for the various polyolefin samples. The line corresponds to the best linear fit.

Figure 7: Mesh Size Distributions measured by thermoporosimetry with cyclohexane for a silicone sample aged in real conditions (-) and a silicone sample vulcanized at $170{ }^{\circ} \mathrm{C}$ for 1 $\min \left(-\triangle^{-}\right)$and $12 \min (-\circ-)$. 


\begin{tabular}{cccccc}
\hline Sample & $\mathrm{SSA}\left(\mathrm{m}^{2} \cdot \mathrm{g}^{-1}\right)$ & $\mathrm{V}_{\mathrm{p}}\left(\mathrm{cm}^{3} \cdot \mathrm{g}^{-1}\right)$ & $\mathrm{R}_{\mathrm{p}}(\AA)$ & $\mathrm{R}_{\mathrm{av}}(\AA)$ & $\Delta \mathrm{T}\left({ }^{\circ} \mathrm{C}\right)$ \\
\hline 1 & 183.1 & 1.327 & 142.5 & 145 & $-11,24$ \\
2 & 166.2 & 0.991 & 87 & 119 & $-13,16$ \\
3 & 472.7 & 0.922 & 34.2 & 39 & $-34,48$ \\
4 & 532 & 0.696 & 24 & 26 & $-55,56$ \\
\hline
\end{tabular}

Table 1: Textural data of the four nanoporous silica gels used for calibration and measured $\Delta \mathrm{T}$ values.

\begin{tabular}{cccc}
\hline $\mathrm{n}$ in $\mathrm{C}_{\mathrm{n}} \mathrm{H}_{2 \mathrm{n}+2}$ & $\mathrm{t}(\AA)$ & Solvent & $\mathrm{t}(\AA)$ \\
\hline 6 & 18.5 & o-xylene & 18.1 \\
7 & 13.5 & m-xylene & 17.9 \\
10 & 9.4 & p-xylene & 19.1 \\
12 & 8.5 & p-Dichlorobenzene & 14.6 \\
& & Trichlorobenzene & 14.7 \\
& & Naphtalene & 13.5 \\
\hline
\end{tabular}

Table 2: thickness of the adsorbed layer $\mathrm{t}$ for various solvents derived from calibration. 


\begin{tabular}{ccc}
\hline Irradiation dose $(\mathrm{kGy})$ & $\mathrm{G}$ & $\mathrm{R}_{\mathrm{Max}}(\AA)$ \\
\hline 1000 (electrons) & 3.86 & 104 \\
$940(\gamma)$ & 9.01 & 600 \\
$830(\gamma)$ & 11.45 & 719 \\
$620(\gamma)$ & & 961 \\
\hline
\end{tabular}

Table 3: Irradiation doses, swelling ratio $\mathrm{G}$ and maximum of Mesh Size Distribution $\mathrm{R}_{\mathrm{Max}}$ for the polyolefin samples. 


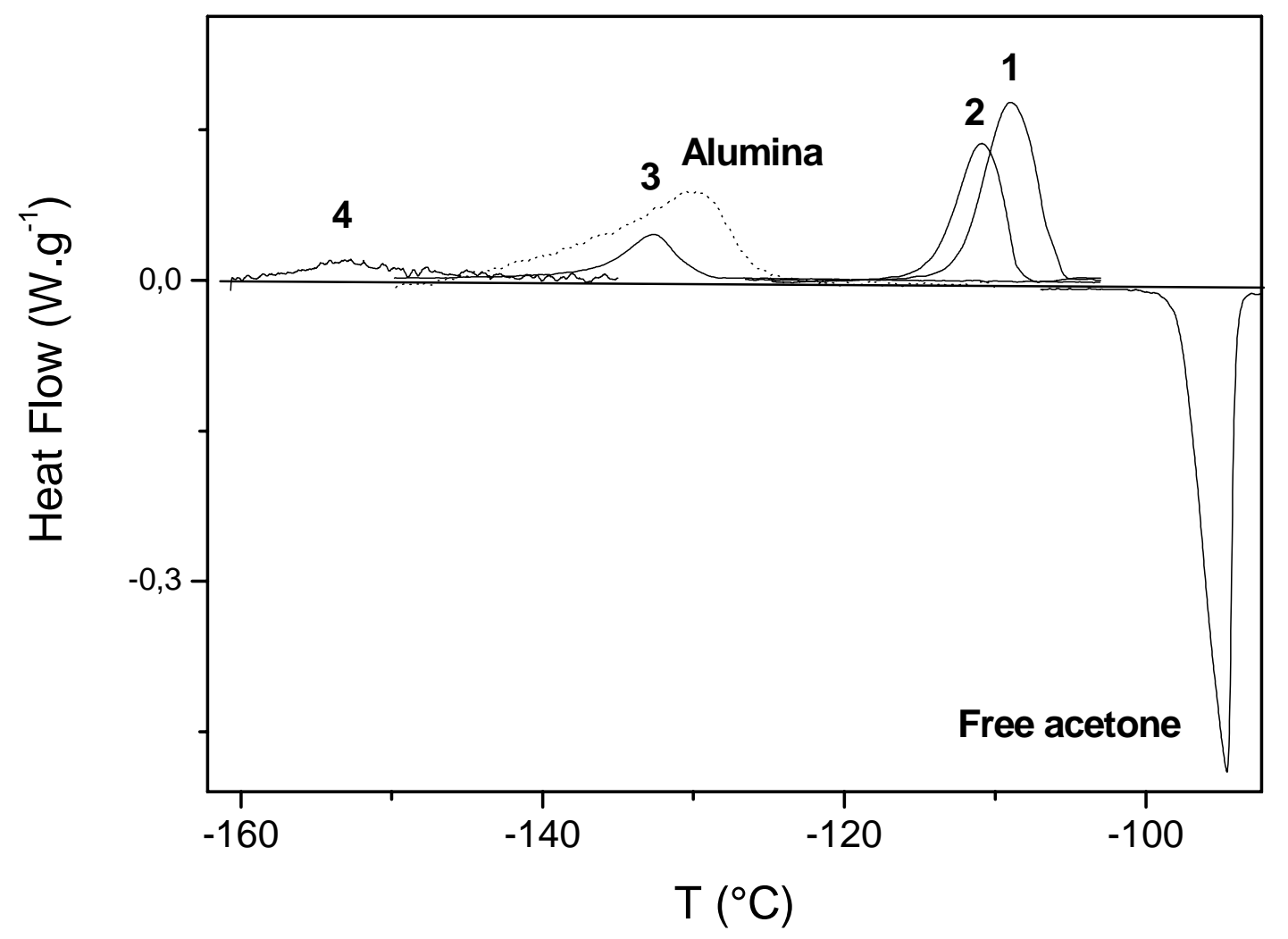

Figure 1: DSC curves recorded for free acetone and acetone confined in silica gels 1-4 and in porous alumina (dotted line). 

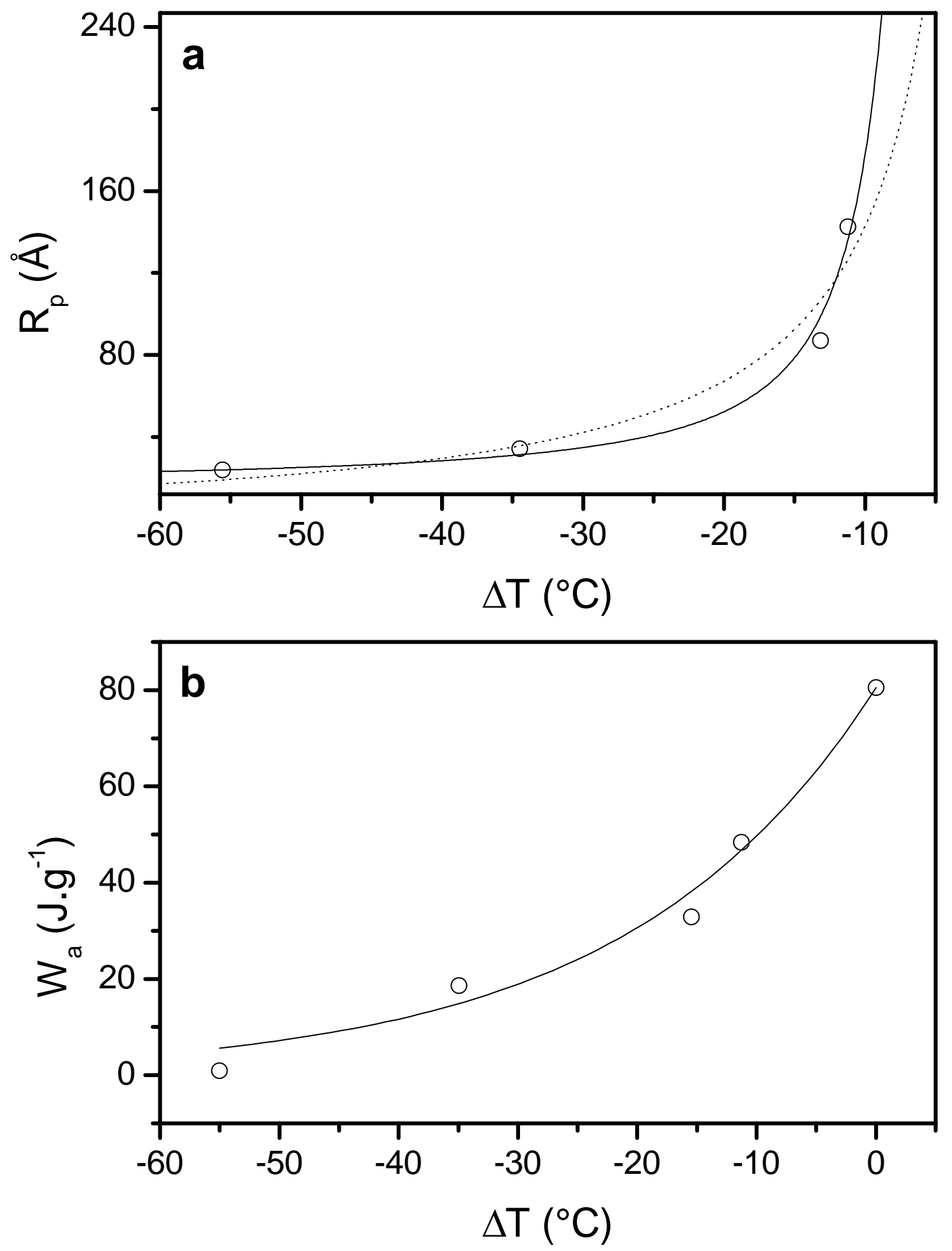

Figure 2: Calibration curves of acetone using silica gels 1-4 for $\mathrm{R}_{\mathrm{p}}$ with Kelvin model (dotted line) and our model (continuous line) (Figure 2a) and $\mathrm{W}_{\mathrm{a}}$ (Figure 2b) 


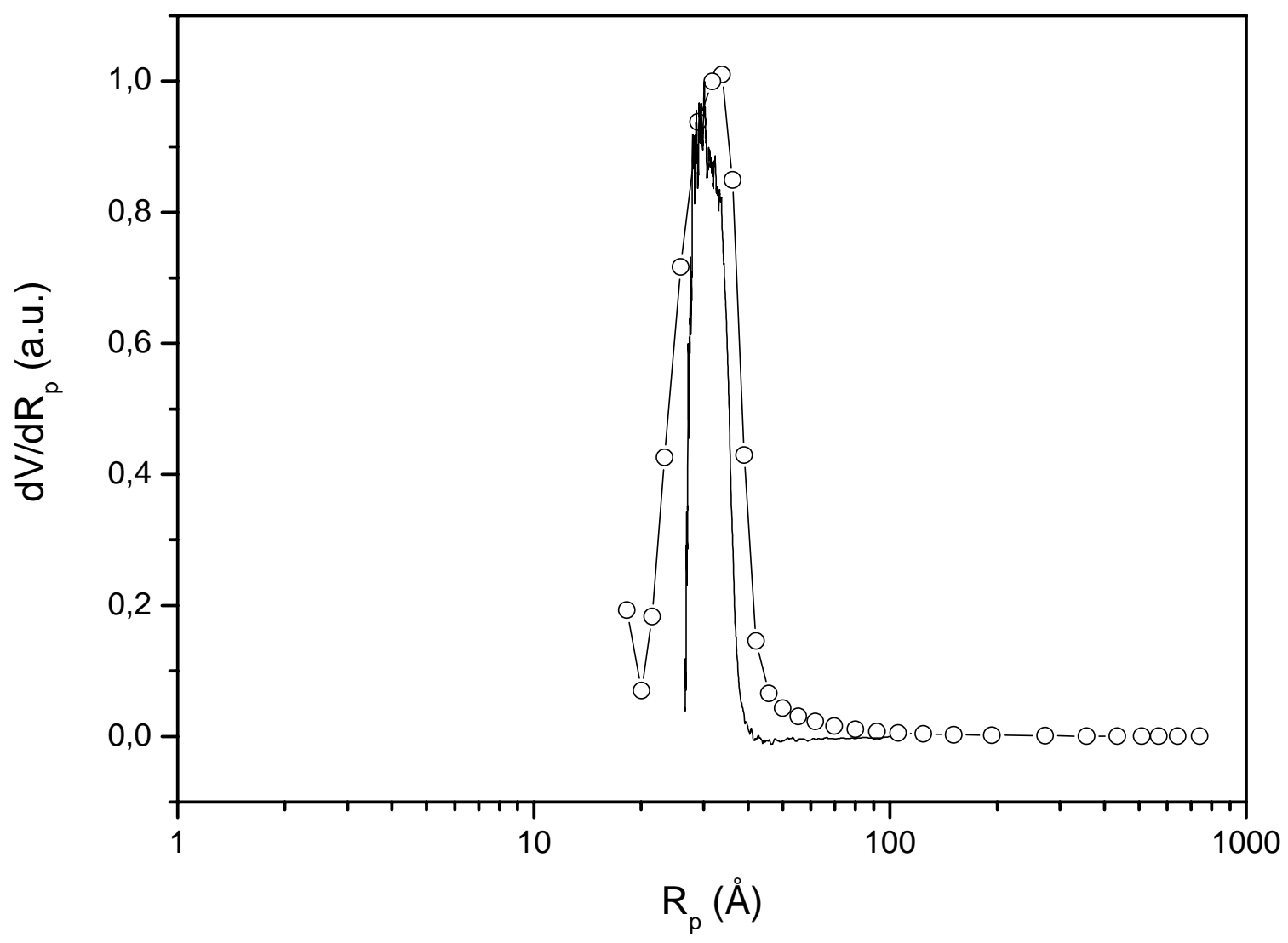

Figure 3: Pore Size Distributions of reference porous alumina sample measured by nitrogen gas sorption (-o-) and by thermoporosimetry with acetone (-) 


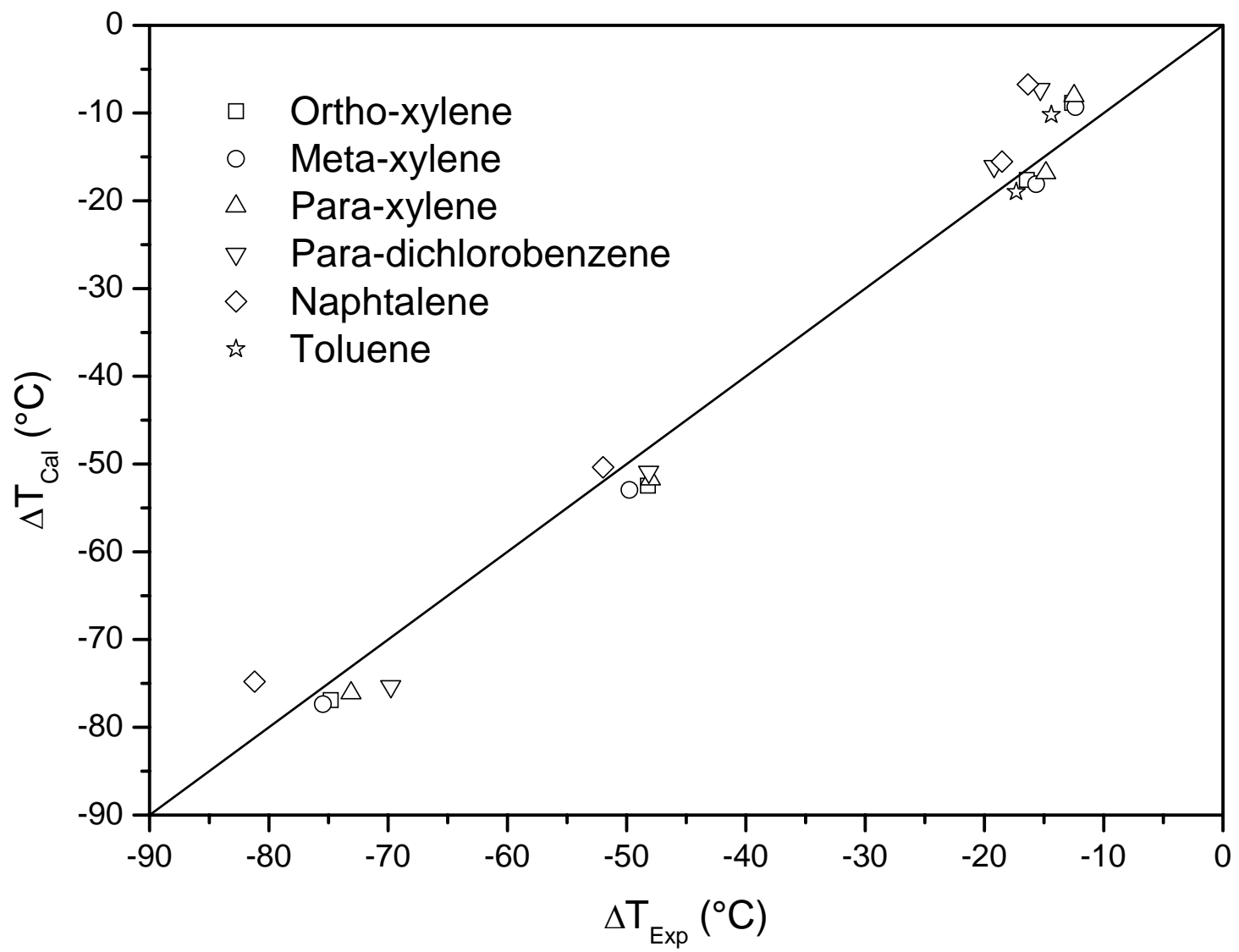

Figure 4: Correlation between experimental values of $\Delta \mathrm{T}$ measured with DSC $\left(\Delta \mathrm{T}_{\exp }\right)$ and the $\Delta \mathrm{T}$ values predicted by our model $\left(\Delta \mathrm{T}_{\text {cal }}\right)$ for various aromatic solvents. 


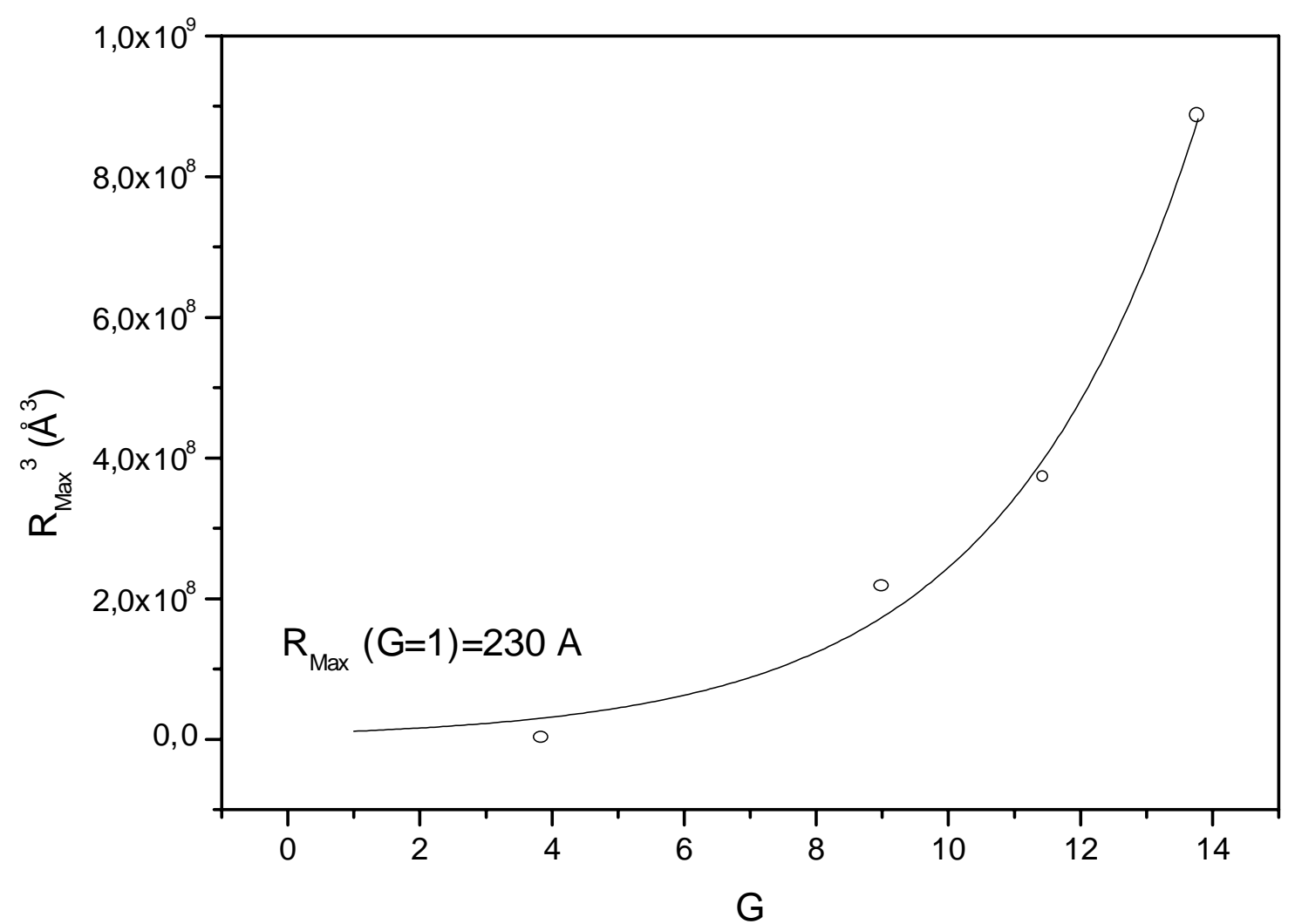

Figure 5: Correlation between $\mathrm{R}_{\mathrm{Max}}{ }^{3}$ and the swelling ratio $\mathrm{G}$ for the various polyolefin samples. The line corresponds to the best exponential growth fit. 


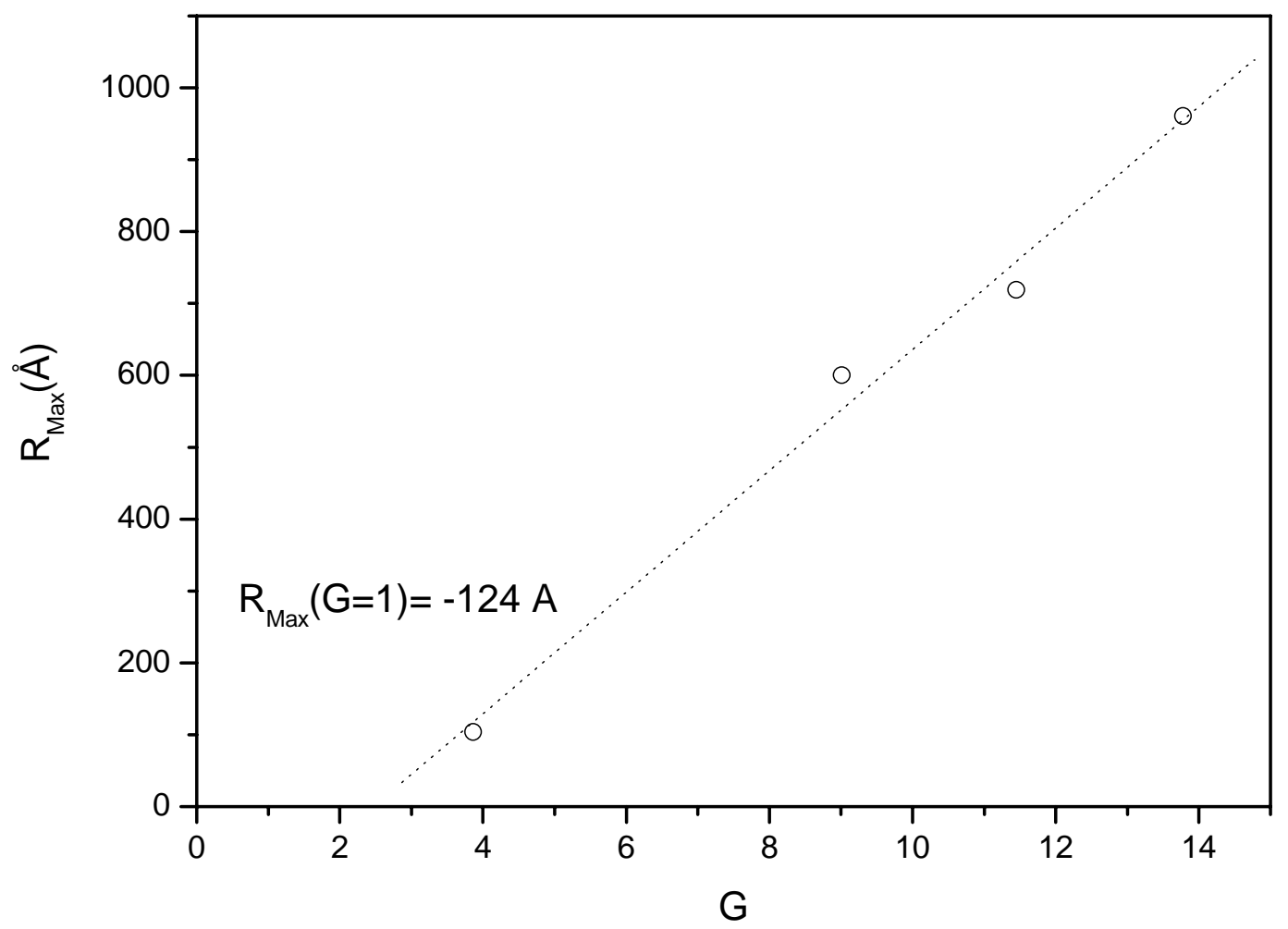

Figure 6: Correlation between $\mathrm{R}_{\mathrm{Max}}$ and the swelling ratio $\mathrm{G}$ for the various polyolefin samples. The line corresponds to the best linear fit. 


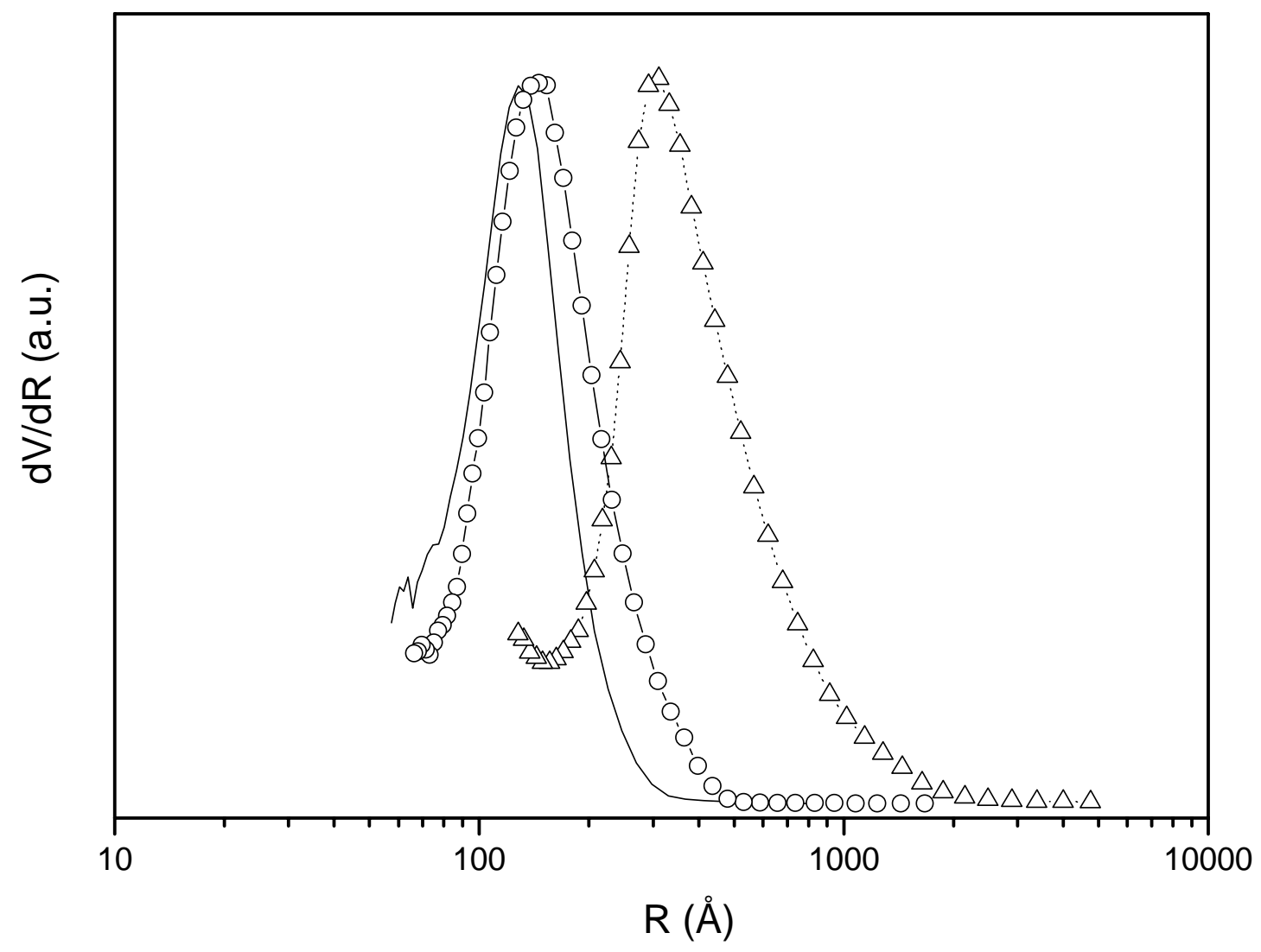

Figure 7: Mesh Size Distributions measured by thermoporosimetry with cyclohexane for a silicone sample aged in real conditions (-) and a silicone sample vulcanized at $170{ }^{\circ} \mathrm{C}$ for 1 $\min (-\triangle-)$ and $12 \min (-\circ-)$. 
Contact author for correspondence and return of proofs:

Dr Jean-Marie Nedelec

Laboratoire des Matériaux Inorganiques (CNRS UMR 6002)

Université Blaise Pascal, 24 Avenue des Landais, 63177 Aubiere, FRANCE

Tel : 0033473407105

Fax 0033473407108

e-mail : j-marie.nedelec@,univ-bpclermont.fr 


\section{References}

[1] J. Gibbs, Collected works, New Haven, CT : Yale University Press, (1928).

[2] S.W. Thomson, Phil. Mag., 42, 448, (1871).

[3] C.L. Jackson, G.B. McKenna, J. Chem. Phys., 93(12), 9002, (1990).

[4]W. Kunh, E. Peterli and H. Majer, J. Polymer Sci., 16, 539, (1955).

[5] G. Fagerlund, Matériaux et constructions 6(33), 215, (1973).

[6] M. Brun, A. Lallemand, J.-F. Quinson and C. Eyraud, Thermochim. Acta, 21, 59, (1977).

[7] E. Derouane, Bull. Soc. Belges 78, 111, (1969).

[8] J. Strange, M. Rahman and E. Smith, Phys. Rev. Lett., 71(21), 3589, (1993).

[9] J.C. Dore, J.B.W. Webber and J.H. Strange, Colloids and Surf. A: Physicochem. Eng. Aspects, 241, 191, (2004).

[10] R.M.E. Valckenborg, L. Pel and K. Kopinga, J. Phys. D : Appl. Phys., 35, 249, (2002).

[11] T. Ville-veikko, L. Juhani and J. Jukka J., J. Phys. Chem. B, 109, 757, (2005).

[12] J.H. Strange and J.B.W. Webber, Meas. Sci. Technol., 8, 555, (1997).

[13] J.H. Strange, J.B.W. Webber and S.D. Schmidt, Magnetic Resonance Imaging 14(7/8), 803, (1996).

[14] J.H. Strange and J.B.W. Webber, Applied Magnetic Res., 12(2-3), 231, (1997).

[15] P. Gane, C. Ridgway, E. Lehtinen, R. Valiullin, I. Furo, J. Schoelkopf, H. Paulapuro and J. Daicic, Ind. Eng. Chem. Res., 43, 7920, (2004).

[16] L.L. Hench, in Sol-gel silica : processing, properties and technology transfer, Noyes Publications, New York, (1998).

[17] A.L. McClellan and H.F. Harnsberger, J. Colloid and Int. Sci., 23, 577, (1967).

[18] S. Brunauer, P.H. Emmet and E. Teller, J. Am. Chem. Soc., 60, 309, (1938).

[19] E.P. Barret, L.G. Joiner and P.P. Halenda, J. Am. Chem. Soc., 73, 373, (1951).

[20] R. Landry, Thermochim. Acta, 433(1-2), 27, (2005). 
[21] M. Wulff, Thermochim. Acta, 419, 291, (2004).

[22] T. Takei, Y. Ooda, M. Fuji, T. Watanabe and M. Chikazawa, Thermochim. Acta, 352353, 199, (2000).

[23] B. Husár, S. Commereuc, L. Lukáč, S. Chmela, J.M. Nedelec and M. Baba, J. Phys. Chem. B, 110, 5315, (2006).

[24] N. Billamboz, M. Baba, M. Grivet and J.M. Nedelec, J. Phys. Chem. B, 108, 12032, (2004).

[25] N. Bahloul, M. Baba and J.M. Nedelec, J. Phys. Chem. B, 109, 16227, (2005).

[26] M. Baba, J.M. Nedelec, J. Lacoste and J.L. Gardette, J. Non-Cryst. Solids, 315, 228, (2003).

[27] M. Baba, J.M. Nedelec et al., unpublished results

[28] M. Baba, J.L. Gardette, J. Lacoste, Polymer Degradation and Stability, 65, 415, (1999).

[29] M. Baba, J.M. Nedelec, J. Lacoste, J.L. Gardette and M. Morel, Polymer Degradation and Stability, 80(2), 305, (2003).

[30] G.W. Scherer, J. Non-Cryst. Solids, 155, 1, (1993).

[31] G.W. Scherer, D.M. Smith and D. Stein, J. Non-Cryst. Solids, 186, 309, (1995).

[32] E. Scolan, C. Magnenet, D. Massiot, C. Sanchez, J. Mater. Chem., 9, 2467, (1999). 